\section{Et si la plasticité de reprogrammation du génome était encore plus importante qu'on ne le croyait?}

Stupéfiant rapport dans un très récent article de Science: des cellules souches neurales transplantées par injection intraveineuse à des souris ayant subi une irradiation sublétale sont capables de repeupler la moelle de progéniteurs hématopoïétiques [1]! Ces résultats vont complètement à l'encontre de nos idées sur la question; on considère que les cellules souches tissulaires, hématopoiétiques ou neurogéniques, par exemple, ne peuvent engendrer que des cellules d'un type particulier: granulocytes, hématies, plaquettes, lymphocytes pour les cellules souches hématopoiétiques, neurones, astrocytes, oligodendrocytes pour les cellules souches neurogéniques [2]! Les cellules souches neurales sont prélevées dans le striatum de souris adultes et transplantées, soit directement, soit après clonage, par une injection intraveineuse dans la souris receveuse irradiée de façon sublétale. II faut insister, en outre, sur le fait que cellules hématopoïétiques et neurogéniques procèdent de feuillets embryologiques distincts, respectivement mésodermique et neuroectodermique. Parmi les cellules issues du mésoderme, par exemple, la mutipotentialité est importante: les mêmes cellules souches peuvent donner des cellules cartilagineuses, adipeuses ou musculaires. Ainsi, les résultats récents d'une équipe italienne ont suggéré que des cellules médullaires avaient engendré des progéniteurs musculaires (m/s 1998, $n^{\circ}$ 6-7, p. 803). Déjà fort surprenant, même de la part de cellules de même origine mésodermique! Les travaux décrits aujourd'hui par une équipe italo-canadienne suggèrent que des cellules souches appartenant au feuillet neuroectodermique et engendrant normalement des cellules nerveuses, peuvent également engendrer des cellules sanguines, c'est-àdire des cellules d'origine mésodermique. Si cela se confirmait, cela signifierait que la plasticité de reprogrammation du génome est plus importante qu'on ne croyait. La naissance de Dolly et autres ont montré que le noyau de cellules de différentes origine peut être reprogrammé et redevenir totipotent; les travaux publiés ici suggèrent qu'une reprogrammation d'un type neuroectodermique vers un type mésodermique-hématopoiétique est possible en mettant simplement des cellules neuroectodermiques indifférenciées au contact de l'environnement de la moelle osseuse. Cependant le mécanisme en cause reste incertain. Le travail rapporté dans Science est soigneux mais on ne peut éliminer la possibilité d'artéfacts. II faut se rappeler que le cerveau contient des cellules d'origine mésodermique, les cellules de la microglie qui sont, en fait, des monocytes-macrophages, donc des cellules hématopoïétiques. Cette hypothèse n'est pas très vraisemblable car les auteurs disent avoir cloné leurs cellules souches neurogéniques. Une autre possibilité est que les cellules souches neurogéniques implantées dans la moelle aient été, pour une partie d'entre elles, phagocytées par les cellules médullaires résidentes, persistant après I'irradiation sublétale. Dans ce cas, la " programmation " ressemblerait plus à celle des clonages à la Dolly : le cytoplasme d'une cellule souche hématopoïétique peut, probablement, reprogrammer un noyau neurogénique immature... II se pourrait bien, enfin, que la multipotence des précurseurs neuraux soit beaucoup plus importante que celle des cellules souches des autres tissus. En faveur de cette conception est le fait que des structures mésodermiques (certains muscles faciaux, une partie des os de la face [3]) sont en partie des dérivés de la partie antérieure du tube neural et proviennent bien des cellules neuroectodermiques de la crête neurale. Il se pourrait, par conséquent, que des cellules souches proches de la totipotence des cellules embryonnaires persistent dans le cerveau. Le fait qu'il soit possible de faire des cellules sanguines à partir de cellules cérébrales n'indique d'aucune manière que I'inverse soit vrai. Cela est d'ailleurs malheureux car, dans une éventuelle perspective thérapeutique chez I'homme, prélever des cellules hématopoïétiques est plus aisé qu'obtenir des cellules neurales... Quoi qu'il en soit, cet article vraiment sensationnel va stimuler une fébrile activité dans le monde, au terme de laquelle ces données nouvelles seront confirmées ou infirmées. Si elles sont confirmées, c'est à un ébranlement durable de nos conceptions sur I'irréversibilité des processus de différenciation qu'auraient abouti, coup sur coup, les expériences de clonage par transfert nucléaire de noyaux de cellules différenciées, puis la transdifférenciation neuroectodermique/mésodermique hématopoïétique décrite dans cet article.

\section{Axel Kahn}

[1. Bjornson CRR, Rietze RL, Reynolds BA, Magli MC, Vescovi AL. Turning brain into blood: a hematopoietic fate adopted by adult neural stem cells in vivo. Science 1999; 283 : 534-7.]

[2. Reynolds BA, Weiss S. Generation of neurons and astrocytes from isolated cells of the adult mammalian central nervous system. Science $1992 ; 255: 1707-10$.]

[3. Couly G, Coltey P, Chéron G, Abadie V, Martelli $H$, Le Douarin NM. Rhombomères, code Hox, crête neurale et malformations de la face. Med Sci 1994; 10 : 151-62.] 